\title{
Photoacoustic gas monitoring for anesthetic gas pollution measurements and its cross-sensitivity to alcoholic disinfectants
}

Jennifer Herzog-Niescery ${ }^{1 *}$ D, Thomas Steffens ${ }^{2}$, Martin Bellgardt ${ }^{1}$, Andreas Breuer-Kaiser ${ }^{1}$, Philipp Gude ${ }^{1}$, Heike Vogelsang ${ }^{1}$, Thomas Peter Weber ${ }^{1}$ and Hans-Martin Seipp ${ }^{2}$

\begin{abstract}
Background: Real-time photoacoustic gas monitoring is used for personnel exposure and environmental monitoring, but its accuracy varies when organic solvents such as alcohol contaminate measurements. This is problematic for anesthetic gas measurements in hospitals, because most disinfectants contain alcohol, which could lead to false-high gas concentrations. We investigated the cross-sensitivities of the photoacoustic gas monitor Innova 1412 (AirTech Instruments, LumaSense, Denmark) against alcohols and alcoholic disinfectants while measuring sevoflurane, desflurane and isoflurane in a laboratory and in hospital during surgery.

Methods: $25 \mathrm{~mL}$ ethyl alcohol was distributed on a hotplate. An optical filter for isoflurane was used and the gas monitor measured the 'isoflurane' concentration for five minutes with the measuring probe fixed $30 \mathrm{~cm}$ above the hotplate. Then, $5 \mathrm{~mL}$ isoflurane was added vaporized via an Anesthetic Conserving Device (Sedana Medical, Uppsala, Sweden). After one-hour measurement, $25 \mathrm{~mL}$ isopropyl alcohol, N-propanol, and two alcoholic disinfectants were subsequently added, each in combination with $5 \mathrm{~mL}$ isoflurane. The same experiment was in turn performed for sevoflurane and desflurane. The practical impact of the cross-sensitivity was investigated on abdominal surgeons who were exposed intraoperatively to sevoflurane. A new approach to overcome the gas monitor's cross-sensitivity is presented.

Results: Cross-sensitivity was observed for all alcohols and its strength characteristic for the tested agent. Simultaneous uses of anesthetic gases and alcohols increased the concentrations and the recovery times significantly, especially while sevoflurane was utilized. Intraoperative measurements revealed mean and maximum sevoflurane concentrations of $0.61 \pm 0.26 \mathrm{ppm}$ and $15.27 \pm 14.62 \mathrm{ppm}$. We replaced the cross-sensitivity peaks with the 10th percentile baseline of the anesthetic gas concentration. This reduced mean and maximum concentrations significantly by $37 \%(p<0.001)$ and $86 \%(p<0.001)$, respectively.

Conclusion: Photoacoustic gas monitoring is useful to detect lowest anesthetic gases concentrations, but cross-sensitivity caused one third falsely high measured mean gas concentration. One possibility to eliminate these peaks is the recovery time-based baseline approach. Caution should be taken while measuring sevoflurane, since marked cross-sensitivity peaks are to be expected.
\end{abstract}

Keywords: Gas pollution, Occupational gas exposure, Photoacoustic gas monitoring, Cross-sensitivity, Isoflurane, Sevoflurane, Desflurane, Recovery time

\footnotetext{
* Correspondence: j.herzog-niescery@klinikum-bochum.de

'Department of Anesthesiology, Katholisches Klinikum Bochum,

Ruhr-University Bochum, St. Josef Hospital, Gudrunstraße 56, 44791 Bochum,

Germany

Full list of author information is available at the end of the article
}

(c) The Author(s). 2019 Open Access This article is distributed under the terms of the Creative Commons Attribution 4.0 International License (http://creativecommons.org/licenses/by/4.0/), which permits unrestricted use, distribution, and reproduction in any medium, provided you give appropriate credit to the original author(s) and the source, provide a link to the Creative Commons license, and indicate if changes were made. The Creative Commons Public Domain Dedication waiver (http://creativecommons.org/publicdomain/zero/1.0/) applies to the data made available in this article, unless otherwise stated. 


\section{Background}

Occupational anesthetic gas exposure is attracting growing interest, since studies have shown that low-dose exposure to volatile anesthetics (VA) increases the number of DNA strand breaks and the micronuclei frequencies in lymphocytes and epithelial cells [1, 2]. Although exposure levels of healthcare professionals have been minimized, it still is good clinical practice to reduce gas pollution 'as low as reasonably achievable' [3]. The Occupational Safety and Health Administration of the United States recommends the control of VA exposure by engineering controls, good work practices, use of personal protective equipment, administrative controls, and personnel exposure and environmental monitoring. The latter is especially significant, because it demonstrates the effectiveness of the gas control program and should be performed every six months [4].

Different approaches are available to evaluate the personnel's exposure, but measurements in the individual breathing zones are commonly performed, either by time-integrated or real-time air-sampling. A dosimeter is an example for time-integrated sampling. It measures the mean pollution level, but the minimum sampling duration is $>15 \mathrm{~min}$ and it is not possible to get an instant feedback [4]. Hence, real-time measurements performed by gas analyzers are preferred, because they present mean and maximum concentrations continuously and enable an immediate feedback of the current VA exposure. Their low analytical detection limits allow to detect trace concentrations of $0.005 \mathrm{ppm}$. However, it is known that their accuracy may vary when they are used together with organic solvents such as alcohols [5, 6]. This is problematic for VA measurements in hospitals, because many commonly used substances contain alcohol, which may lead to a misjudgment of the actual pollution (Table 1).

We investigated the cross-sensitivities of a photoacoustic gas monitor against alcohols and alcoholic disinfectants (AD) while measuring isoflurane (ISO), sevoflurane (SEVO), and desflurane (DES) in the air. Characteristic curves and an approach to deal with these interferences are presented.

We hypothesized that there is a cross-sensitivity for all three VA and that the elimination of the cross-sensitivity would reduce the average false-high VA concentration significantly by $30 \%$. This practical impact of the crosssensitivity was investigated on abdominal surgeons who were exposed intraoperatively to sevoflurane.

\section{Methods}

Laboratory experiments were performed at the University of Applied Sciences, Giessen, Germany, in 2018. VA pollution measurements were conducted in a German University hospital (Katholisches Klinikum Bochum, St.
Josef Hospital). The study was approved by the local ethics committee in December 2015 (No. 5184-14; Ethikkommission der Ruhr-Universität Bochum, Germany). Written informed consent was obtained from all participants included in this study. Measurements were performed according to the Declaration of Helsinki.

\section{Photoacoustic gas monitoring}

All measurements were conducted with the photoacoustic gas monitor Innova 1412 (AirTech Instruments, LumaSense, Denmark). This analyzer identifies any gas that absorbs infrared light by using the photoacoustic infrared detection method with specific optical filters. The operating principle is as follows: A pump sucks in a sample of air into a sealed measurement cell, where pulsed infrared laser light is transferred through an optical filter. The monitored gas selectively absorbs the transmitted light, which leads to volume variations caused by increasing and decreasing temperature. This results in an acoustic signal in the measurement cell, which is proportional to the investigated gas concentration.

The gas monitor was calibrated by the manufacturer with optical filters for VA measurements (UA 0970: SEVO and DES, wavelength $8.2 \mu \mathrm{m}$; UA 0971: ISO, wavelength $8.5 \mu \mathrm{m}$ ) and for water vapor (SB0527, lower detection limit $50 \mathrm{ppm})$. Filters for VA measurements had a bandwidth of $6 \%$ and analytical detection limits of $0.006 \mathrm{ppm}$ for SEVO, $0.005 \mathrm{ppm}$ for DES and $0.005 \mathrm{ppm}$ for ISO at $20^{\circ} \mathrm{C}, 1 \mathrm{~atm}$ pressure and for a sample integration time of $5 \mathrm{~s}$. Filters for alcohols were not used in this study to demonstrate any cross-sensitivity. A measurement interval lasted $35 \mathrm{~s}$ and depended on the size of the measurement cell, the length of the sampling probe, time to flush both with fresh air (30s), and on the sample integration time ( $5 \mathrm{~s})$. An autocalibration was performed by the gas monitor prior to each change of the VA filter. According to the manufacturer, the reproducibility of the measured anesthetic gas concentration by the photoacoustic gas monitor is $\pm 1 \%$ of the measured value.

\section{Experimental setup}

The tests were conducted in a laboratory sized $36.5 \mathrm{~m}^{3}$. The door and the windows were kept closed. A hotplate was placed on a table and heated to $37^{\circ} \mathrm{C}$. The measuring probe of the photoacoustic gas monitor was fixed on a stand at a distance of $30 \mathrm{~cm}$ above the hotplate. A fan was used for a uniform distribution of air (Fig. 1).

\section{Baseline values}

First, baseline values for ISO, SEVO and DES were determined to detect any contamination in the air. The gas monitor was calibrated to measure ISO, SEVO or DES, but neither VAs, nor interfering agents were used. A measurement interval lasted $10 \mathrm{~min}$ each. 
Table 1 Commonly used disinfectants and alcoholic components which may be interfering substances while using the gas monitor. $\mathrm{n}$ (right column) = number of alcoholic components

\begin{tabular}{|c|c|c|c|c|c|c|c|c|}
\hline Alcohol / Disinfectant & Ethyl alcohol & Isopropyl alcohol & N-propanol & Benzyl alcohol & 1-tetra-decanol & Biphenyl-2-ol & Glycerol & \\
\hline \multicolumn{8}{|c|}{ Hand disinfection (hygienic or preoperative) } & $n$ \\
\hline Ethyl alcohol 80 vol.\% & $\mathrm{X}$ & & & & & & & 1 \\
\hline Isopropyl alcohol 70 vol.\% & & $\mathrm{x}$ & & & & & & 1 \\
\hline N-propanol 60 Vol.\% & & & $\mathrm{x}$ & & & & & 1 \\
\hline AHD $2000^{\oplus}$ & $\mathrm{x}$ & & & & & & & 1 \\
\hline Aktivin $^{\circledast} \mathrm{DHH}$ & & $\mathrm{x}$ & & & & & & 1 \\
\hline Aseptoman ${ }^{\oplus}$ & & $\mathrm{x}$ & & & & & & 1 \\
\hline Aseptoman ${ }^{\oplus}$ viral & $\mathrm{x}$ & & $x$ & & & & & 2 \\
\hline Aseptopur ${ }^{\oplus}$ & & $\mathrm{X}$ & & & & & & 1 \\
\hline Descoderm $^{\oplus}$ & & $\mathrm{X}$ & & & & & & 1 \\
\hline Desderman ${ }^{\oplus}$ pure & $\mathrm{X}$ & $\mathrm{x}$ & & & & $\mathrm{x}$ & & 3 \\
\hline Hospisept $^{\circledast}$ & $\mathrm{x}$ & & $\mathrm{x}$ & & & & & 2 \\
\hline Poly-Alcohol Hands Antiseptic & & $\mathrm{X}$ & & & & & & 1 \\
\hline Promanum pure ${ }^{\oplus}$ & $\mathrm{x}$ & $\mathrm{x}$ & & & & & & 2 \\
\hline Skinman ${ }^{\circledast}$ clear & & & $\mathrm{x}$ & & & & $\mathrm{X}$ & 2 \\
\hline Skinman ${ }^{\circledR}$ complete & $\mathrm{x}$ & & & & & & & 1 \\
\hline Skinman ${ }^{\circledast}$ complete pure & $x$ & & & & & & & 1 \\
\hline Skinman ${ }^{\circledast}$ soft & & $\mathrm{x}$ & & & $\mathrm{x}$ & & & 2 \\
\hline Skinsept ${ }^{\oplus} F$ & & $\mathrm{x}$ & & & & & & 1 \\
\hline Softa-Man ${ }^{\oplus}$ & $x$ & & $x$ & & & & & 2 \\
\hline Softa-Man ${ }^{\oplus}$ acute & $x$ & & $\mathrm{x}$ & & & & & 2 \\
\hline Spitacid $^{\circledR}$ & $x$ & $x$ & & $\mathrm{x}$ & & & & 3 \\
\hline Sterillium ${ }^{\circledast}$ & & $\mathrm{x}$ & $\mathrm{x}$ & & $x$ & & & 3 \\
\hline Sterillium $^{\oplus}$ classic pure & & & $\mathrm{x}$ & & $\mathrm{x}$ & & & 2 \\
\hline Sterillium ${ }^{\circledR}$ med & $x$ & & $\mathrm{x}$ & & $\mathrm{x}$ & & & 3 \\
\hline Sterillium ${ }^{\circledast}$ virugard & $x$ & & & & $\mathrm{x}$ & & & 2 \\
\hline \multicolumn{9}{|l|}{ Skin antiseptics } \\
\hline Cutasept $^{\oplus}-\mathrm{F},-\mathrm{G}$ & & $x$ & & & & & & 1 \\
\hline Kodan $^{\circledast}$ tincture forte & & $\mathrm{x}$ & $\mathrm{x}$ & $\mathrm{x}$ & & $\mathrm{x}$ & & 4 \\
\hline Octeniderm $^{\oplus}$ & & $\mathrm{x}$ & $x$ & & & & & 2 \\
\hline Poly Alcohol colourless & & $x$ & & & & & & 1 \\
\hline \multicolumn{9}{|l|}{ Surface disinfection } \\
\hline Amocid Lysoform ${ }^{\circledast}$ & & & & & & $x$ & & 1 \\
\hline Bacillol ${ }^{\oplus} \mathrm{AF}$ & $x$ & $\mathrm{X}$ & $\mathrm{x}$ & & & & & 3 \\
\hline Mikrozid $^{\circledR}$ AF liquid & $x$ & & $x$ & & & & & 2 \\
\hline Total [n] & 15 & 17 & 13 & 2 & 5 & 3 & 1 & \\
\hline
\end{tabular}

\section{Volatile anesthetics}

An Anesthetic Conserving Device (ACD; Sedana Medical, Uppsala, Sweden) was used to vaporize the VAs. Therefore, a compressed air bottle with a flow rate of $480 \mathrm{~L} / \mathrm{h}$ was combined with the ACD, which was flushed with liquid VA (6 in Fig. 1). The gas monitor was equipped with the optical filter for the VA of interest. As soon as the VA concentration in the air had reached the baseline value, a bolus of 5 $\mathrm{mL}$ liquid VA was injected into the ACD and the gas pollution measured for one hour. Regression lines, which appear as linear curves when using a semi logarithmic diagram, were calculated after the maximum concentration was reached by the formula $\mathrm{c}=\mathrm{a}$ - exp. $(-b \cdot t)$ with c: VA concentration [ppm]; a: factor to calculate the regression; $b$ : gradient; $t$ : time. 


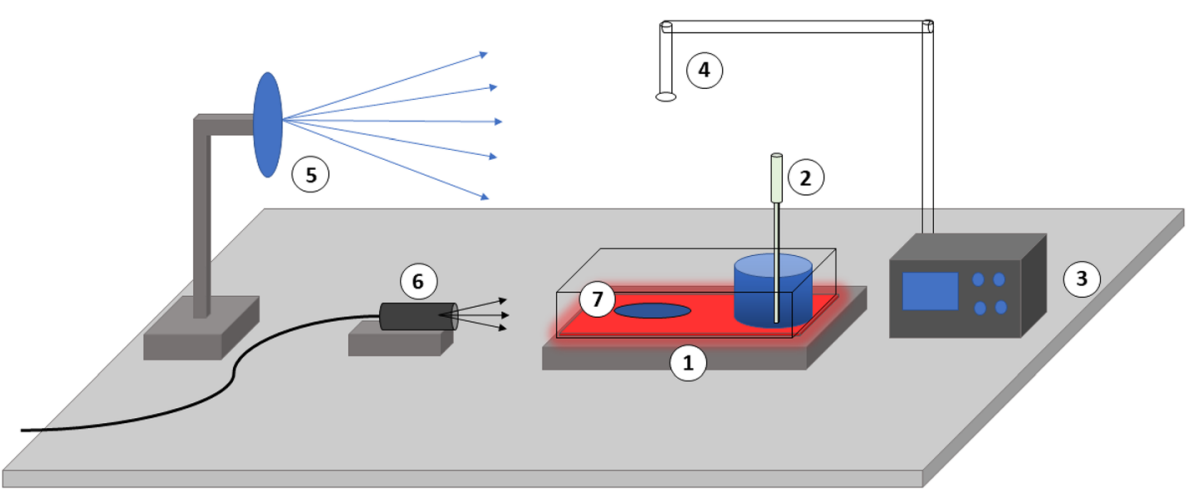

Fig. 1 Experimental setup. A hotplate (1) was heated to $37^{\circ} \mathrm{C}$ and its temperature controlled by a thermometer (2). The gas monitor's (3) measuring probe was fixed on a stand (4). A fan was used for a uniform distribution of air (5). An Anesthetic Conserving Device was used for vaporization of the volatile anesthetic (6). The interfering agents were distributed on the hotplate (7)

\section{Volatile anesthetics and interfering agents}

An optical filter for ISO was used and $25 \mathrm{~mL}$ ethyl alcohol was distributed on the hotplate. After ten minutes of measurement, $5 \mathrm{ml}$ ISO was injected into the ACD as described above, followed by a one-hour measurement. Subsequently, $25 \mathrm{~mL}$ isopropyl alcohol, N-propanol, AD I (isopropyl alcohol $45 \mathrm{vol} \%$, N-propanol $30 \mathrm{vol} \%$ ), and AD II (isopropyl alcohol $72 \mathrm{vol} \%$ ) were added, each agent in combination with $5 \mathrm{~mL}$ ISO. Regression lines were calculated as described above.

The same tests were in turn performed with SEVO and DES.

\section{Approach to eliminate cross-sensitivity peaks}

The approach is based on the recovery time, which is the time needed to reduce the gas concentration in the room by two log steps (corresponds to a reduction of 99\%). The recovery time was calculated according to DIN EN ISO 14644 [7] and depended primarily on the type of air-conditioning, the supply air volume, the volume of the operating room, and on the position of the exhaust air slots.

To demonstrate practical significance of this approach, the gas monitor was calibrated for SEVO and the VA exposure measured during abdominal surgery in the surgeons' individual breathing zones $(25 \mathrm{~cm}$ around nose and mouth). The use of interfering agents was documented in time. VA concentrations and cross-sensitivity peaks were analyzed and the 'actual' SEVO pollution estimated.

\section{Statistical analysis}

IBM SPSS version 20 (IBM Corp., Armonk, NY) was used for statistical analysis. After testing variables for normality using the Kolmogorov-Smirnov test and Lilliefors correction, statistical significance was determined using Students t-test and Mann-Whitney U test. Linear regression analysis was performed. Continuous variables are shown as mean (standard deviation (SD)) or median (interquartile range (IQR)). A $p$-value $<0.05$ (two-sited test, error probability $<5 \%$ ) was considered statistically significant.

The sample size required for measurements in hospital is based on a pilot study of 10 surgeons, who were exposed to a mean SEVO concentration of $0.58 \pm 0.27 \mathrm{ppm}$ including cross-sensitivity. For an $\alpha$-risk of 0.05 with a power of $80 \%$ at least 16 measurements are needed to demonstrate a $30 \%$ reduction of the average SEVO concentration by elimination of the cross-sensitivity.

\section{Results \\ Baseline values}

Mean \pm SD baseline values were $0.05 \pm 0.01$ (median: 0.05, IQR: 0.001) ppm for ISO, $0.01 \pm 0.01$ (median: 0.01, IQR: 0.001$) \mathrm{ppm}$ for SEVO, and $0.04 \pm 0.01$ (median: 0.05, IQR: 0.001$) \mathrm{ppm}$ for DES ( $n=5$ per VA).

\section{Volatile anesthetics}

The concentrations of all three VAs increased within approximately five minutes to a maximum of 21.01-23.99 ppm. The decay curves corresponded to recovery times of 52 min and exponential functions with $R^{2}=0.999$ for ISO, $\mathrm{R}^{2}=0.995$ for $\mathrm{SEVO}$, and $\mathrm{R}^{2}=0.999$ for DES) $(\mathrm{n}=5$ per VA) (Fig. 2).

\section{Volatile anesthetics and interfering agents}

The gas monitor detected VA concentrations, although only alcohols and $\mathrm{AD}$ were used $(n=5$ per interfering agent and for each VA) (Fig. 3 a-c). Consistently, highest cross-sensitivity peaks were caused by isopropyl alcohol, followed by AD, ethyl alcohol and N-propanol.

The simultaneous use of VA and interfering agent led to a false-high 'VA concentration' and extended the recovery time (Fig. 3d). Further, the strength of the crosssensitivity reaction was influenced by the measured VA (SEVO > DES, ISO) (Table 2). 


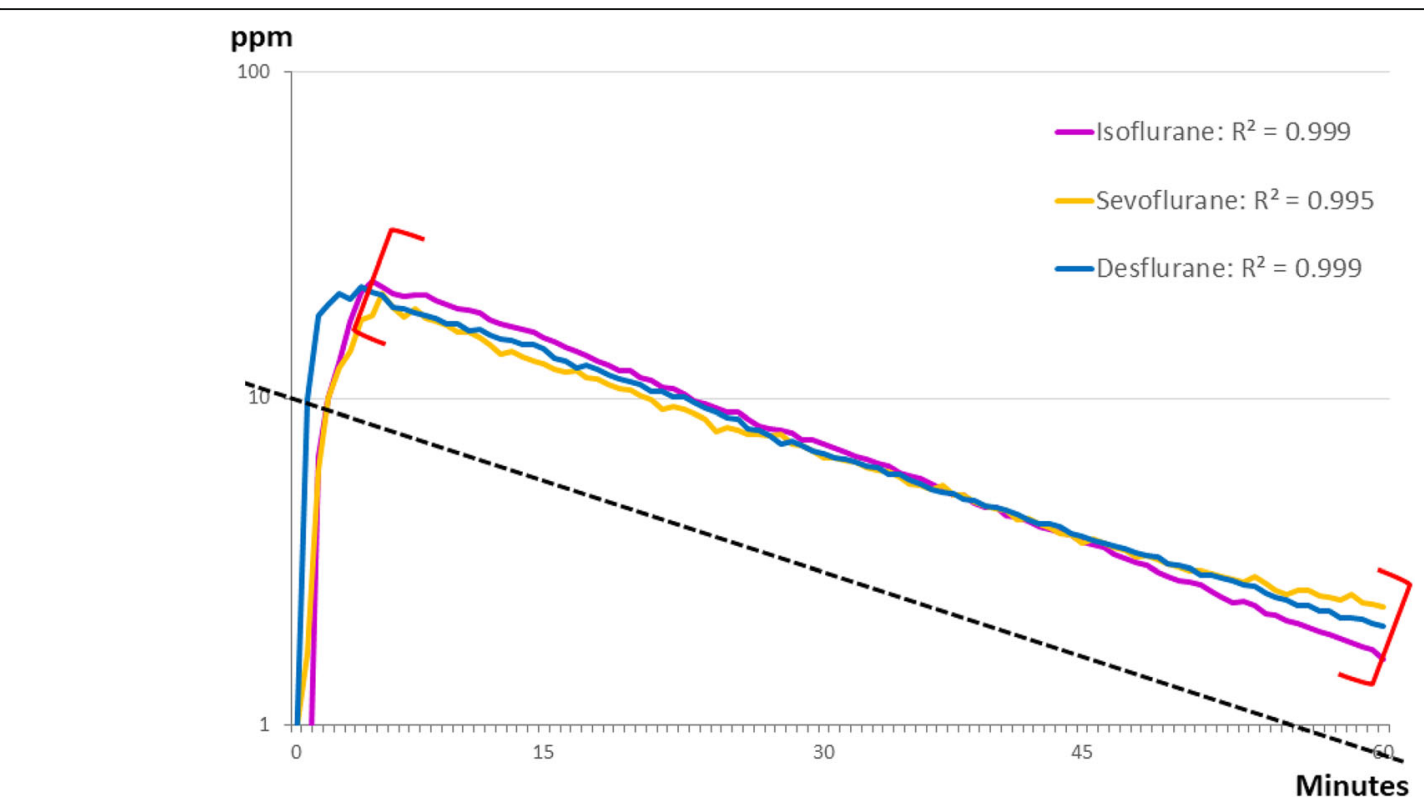

Fig. 2 Decay curves were similar for all gases (isoflurane: $y=29.691$ e-0.028x; sevoflurane: $y=22.508 e-0.024 x$; desflurane: $y=24.956 e-0.025 x$ ). $R^{2}$ : exponential function with linear regression; calculations started after the maximum concentration was reached (red brackets). The recovery time was 52 min (dotted black line). $N=5$ per anesthetic gas

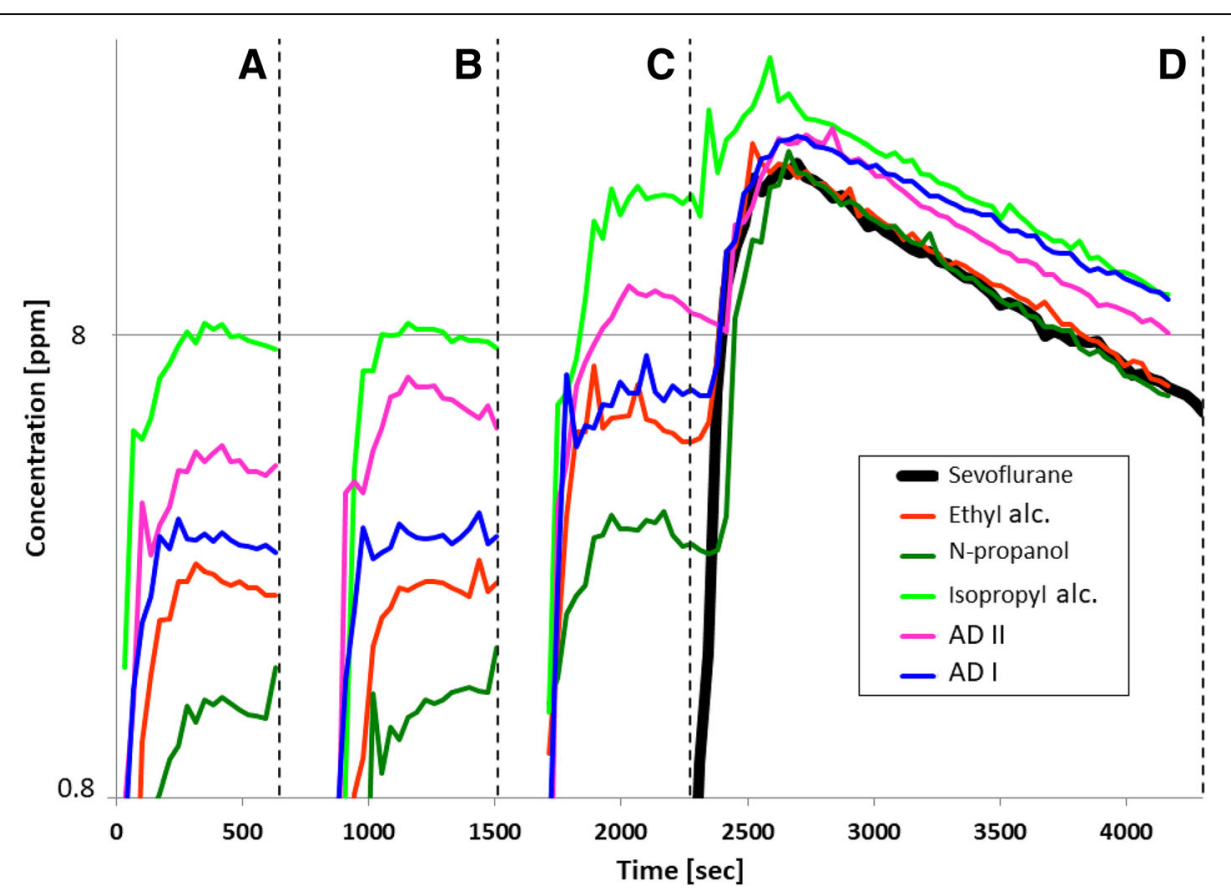

Fig. 3 The gas monitor with filters for isoflurane (a), desflurane (b), or sevoflurane (c) mistakenly detects anesthetic gases, although alcohols and alcoholic disinfectants (ad) were used ( $n=5$ per interfering agent). The strength of the cross-sensitivity was highest for isopropyl alcohol (alc.). $\mathbf{d}$ shows the increase of the actual sevoflurane concentration (black line) by interfering agents 
Table 2 Impact of the volatile anesthetic on the strength of the cross-sensitivity reaction for different interfering substances. Boldface entries refer to a significant value (level of significance: $p<0.05$ ). ${ }^{*}=$ sevoflurane caused higher false-high 'VA' pollution levels than desflurane or isoflurane; \#= desflurane caused higher false-high 'VA' pollution levels than isoflurane. $N=5$ per interfering agent and for each VA

\begin{tabular}{|c|c|c|c|c|c|c|c|c|c|c|}
\hline \multirow{2}{*}{$\begin{array}{l}\text { Anesthetic } \\
\text { gas }\end{array}$} & \multicolumn{5}{|l|}{ Desflurane } & \multicolumn{5}{|l|}{ Sevoflurane } \\
\hline & Ethyl alcohol & N-propanol & Isopropyl alcohol & AD I & $A D \|$ & Ethyl alcohol & N-propanol & Isopropyl alcohol & AD I & $A D \|$ \\
\hline Isoflurane & $0.042 \#$ & 0.329 & 0.383 & 0.457 & $<0.001 \#$ & $<0.001^{*}$ & $<0.001^{*}$ & $<0.001^{*}$ & $<0.001^{*}$ & $<0.001^{*}$ \\
\hline Sevoflurane & $<0.001 *$ & $<0.001 *$ & $<0.001 *$ & $<0.001 *$ & $<0.001 *$ & - & - & - & _- & - \\
\hline
\end{tabular}

\section{Approach to eliminate cross-sensitivity peaks}

SEVO exposure in surgeon breathing zone $(n=20)$ was not distinguished between VA and interfering agents. The false-high mean and maximum SEVO concentrations were $0.61 \pm 0.26 \mathrm{ppm}$ and $15.27 \pm 14.62$ ppm, respectively.

To overcome cross-sensitivity, a 10th percentile baseline is drawn for logarithmic data with recovery time marked. A straight line is drawn from the upper left corner $(0 / \log 10$; intersection $\mathrm{X}$-Y-axis) to the $\mathrm{X}$-axis and moved to the peak's maximum. The intersection with the curve marks the end of the cross-sensitivity peak.
This time interval is replaced by the baseline concentration (Fig. 4).

This technique resulted in corrected mean and maximum SEVO concentrations of $0.38 \pm 0.09 \mathrm{ppm}$ and $0.91 \pm 0.49 \mathrm{ppm}$, respectively, which is a significant reduction of $38 \%$ for mean $(p<0.001)$ and $86 \%$ for maximum $(p<0.001)$ SEVO concentrations.

\section{Discussion}

This study investigated a photoacoustic gas monitor's cross-sensitivities against alcohols and AD while measuring VA pollution.

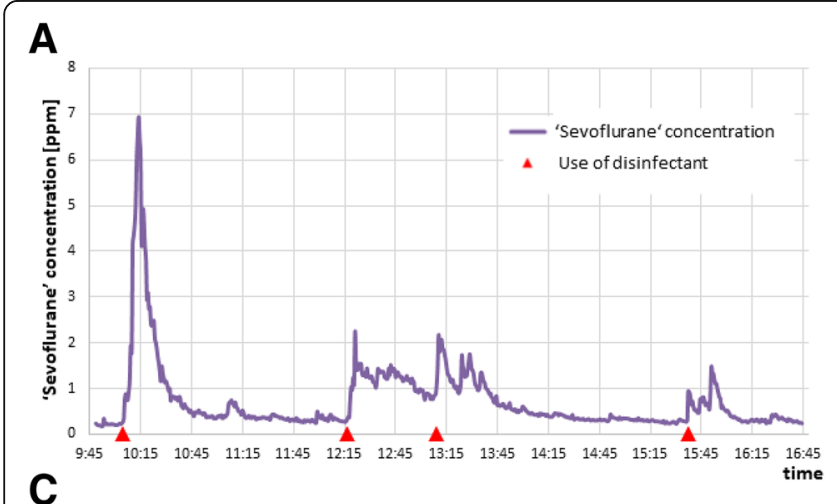

B
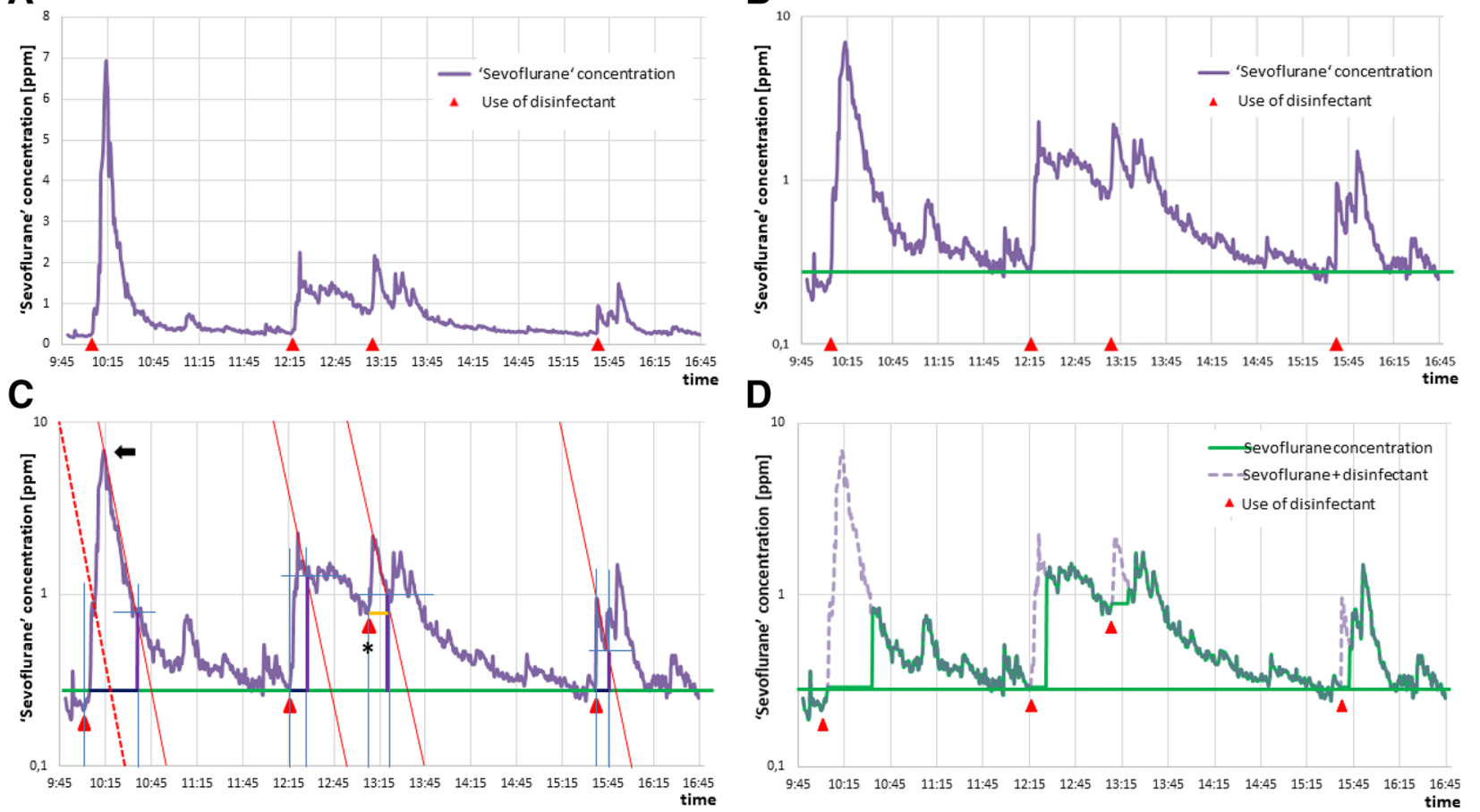

Fig. 4 Approach to eliminate cross-sensitivity peaks. a shows the false-high 'sevoflurane exposure' of a surgeon (purple line; [ppm] mean: $0.73 \pm$ 0.70, maximum: 6.93; red triangle: use of disinfectant). After logarithmic presentation of the data (purple line in $\mathbf{b}$ ), the 10th percentile baseline is drawn (green line; here $0.29 \mathrm{ppm}$ ), and the recovery time is marked (red dotted line in $\mathbf{c}$; here $39 \mathrm{~min}$ ). This line is moved to the peak's maximum (black arrow in c). The intersection with the curve marks the end of the cross-sensitivity peak (blue cross in c). This time interval is replaced by the baseline concentration (dark blue line in c). If interfering agents are used before the decay curve has reached the baseline concentration (back star in c) the cross-sensitivity interval should not be replaced by the 10th percentile, but by the measured concentration at the beginning of the cross-sensitivity peak (orange in $\mathbf{c}$ ). In this example the 'corrected' mean and maximum sevoflurane concentrations were $0.53 \pm 0.33$ ppm and $1.76 \mathrm{ppm}$, which is a reduction by $28 \%$ (d) 
In principle, photoacoustic gas monitoring is an excellent method to detect waste anesthetic gases in the air. The low detection limits allow for identification of the smallest concentrations of VAs and the immediate feedback of the VA exposure makes the gas monitor valuable in practice, because it may attract attention and help reduce the occupational gas burden. However, its cross-sensitivity to alcohols is problematic, because interfering agents are regularly used in the perioperative setting (e.g. for skin disinfection or surgical hand disinfection). This study aimed to investigate this phenomenon, since it is not considered in most clinical studies and the false-high 'VA' concentrations may stir unjustified fears [8-11].

The photoacoustic gas monitor's manufacturer advises that cross-sensitivities may occur, but no information is given about the impact of the interfering agent on the measured value, the decay curve, or its significance in the clinical environment [12]. Instead, the use of additional optical filters is recommended, but this assumes that all interfering agents are known. Although it is a possible approach in an experimental setting, this is difficult in hospitals. The gas monitor can simultaneously be used with filters for the VA, water vapor, and up to four alcohols. However, this still may be insufficient as other substances interferer as well (e.g. permanent marker: ethyl alcohol and 4-chloro-3-methylphenol). Another restriction is the high costs of the optical filters. Therefore, an alternative method should be known to eliminate cross-sensitivity peaks. The presented approach can be quickly performed without technical equipment; even the recovery time can be verified in the appropriate documents for every operating room (according to ISO 14644-3 for turbulent ventilation systems) [7].

Our experiences suggest that this approach is suitable for high, as well as low cross-sensitivity peaks. Its particular value is that it considers the cross-sensitivity's maximum, which falsely increase the mean VA concentration mostly. Each peak is replaced by the 10th percentile baseline and not just waived, which takes the actual VA concentration into account. However, it should be noted that the VA pollution during cross-sensitivity peaks is not measured but estimated. Thus, it is possible that the actual VA concentration is higher than the baseline value during a cross-sensitivity peak, which is a limitation (corrections lead to false-low VA concentrations).

In this study the elimination of the cross-sensitivity reduced the false-high mean and maximum 'VA' concentration by 37 and $86 \%$, respectively. These percentages could be higher, if larger amounts of disinfectants are used [5]. This demonstrates the great impact of the cross-sensitivity on VA measurements.
Another finding was that the strength of the cross-sensitivity reaction was influenced by the measured anesthetic gas (SEVO > DES, ISO). This can be explained by the VA's different infrared spectra, which range between 3.2 and $3.6 \mu \mathrm{m}$, but the absorption is highest for SEVO [12]. Consequently, it is most important to consider the gas monitor's cross-sensitivity while measuring SEVO.

This study has a few limitations. First, we demonstrated the gas monitor's cross-sensitivity for selected alcohols and disinfectants only, which are regularly used in hospitals. Isopropyl alcohol caused strongest peaks, however, other alcohols might show different cross-sensitivity characteristics. Further, we used $25 \mathrm{~mL}$ in the experimental setting only, although larger amounts are usually used in clinical routine. Much larger amounts would have increased the time to eliminate the alcohol out of the room, which correlates with increased falsehigh VA measurements. Nevertheless, this would not affect the approach to eliminate the cross-sensitivity peaks. Thirdly, for accuracy of the presented method, the use of every interfering agent must be documented. This might be difficult for substances, which contain 'veiled' interfering agents (e.g. permanent markers). Furthermore, measurements of the baseline values demonstrated that trace concentrations of interfering agents are always detectable, even in an experimental setting. Lastly, the ACD is not registered for DES, because it can boil in the agent line due to its low boiling point, which may result in an unintended emission of gas boluses [3]. However, we did not observe an uneven discharge of the anesthetic.

\section{Conclusions}

Photoacoustic gas monitoring is an excellent method to detect trace concentrations of anesthetic gases, but clinicians are often unaware of its cross-sensitivity and overestimate VA pollution levels. This can be avoided by measurements with different optical filters or by posthoc corrections using the described recovery time-based approach, which had reduced the false-high mean VA concentration by one third and the maximum concentration by $86 \%$ on average in this study. Caution should be taken while measuring SEVO concentrations, since marked cross-sensitivity peaks are to be expected.

\section{Abbreviations}

ACD: Anesthetic Conserving Device; AD: Alcoholic disinfectants; DES: Desflurane; IQR: Interquartile range; ISO: Isoflurane; SD: Standard deviation; SEVO: Sevoflurane; VA: Volatile anesthetic

\section{Acknowledgements}

Not applicable.

\section{Authors' contributions}

JHN planned the experiments and the study in hospital, is responsible for ethical approval, collected, analyzed and interpreted the data, and wrote the 
manuscript. TS planned the experimental part of the study and interpreted the data regarding the cross-sensitivity. MB collected the data during surgery in hospital and helped with the statistical analysis. ABK is responsible for data collection and analysis in hospital. PG prepared the figures and was a major contributor in writing the manuscript. HV prepared the tables, collected data in hospital and revised the manuscript critically. TPW interpreted the data and revised the manuscript. HMS conducted the experiments in the laboratory, analyzed and interpreted the data, developed the recovery-time based approach and helped writing the manuscript. All authors read and approved the final manuscript.

\section{Authors' information}

Not applicable.

\section{Funding}

No funding was obtained for this study.

\section{Availability of data and materials}

The datasets used and/or analyzed during the current study are available from the corresponding author on reasonable request.

\section{Ethics approval and consent to participate}

Laboratory experiments were performed at the University of Applied Sciences, Giessen, Germany, in 2018. Environmental VA pollution measurements were conducted in a German University hospital (Katholisches Klinikum Bochum, St. Josef Hospital). The study was approved by the local ethics committee in December 2015 (No. 5184-14; Ethikkommission der Ruhr-Universität Bochum, Germany). Written informed consent was obtained from all participants included in this study. Measurements were performed according to the Declaration of Helsinki.

\section{Consent for publication}

Not applicable.

\section{Competing interests}

The authors declare that they have no competing interests.

\section{Author details}

${ }^{1}$ Department of Anesthesiology, Katholisches Klinikum Bochum, Ruhr-University Bochum, St. Josef Hospital, Gudrunstraße 56, 44791 Bochum, Germany. ${ }^{2}$ Department of Life Science Engineering, University of Applied Sciences, Giessen, Germany.

Received: 10 January 2019 Accepted: 6 August 2019

Published online: 09 August 2019

\section{References}

1. Çakmak G, Eraydın D, Berkkan A, Yağar S, Burgaz S. Genetic damage of operating and recovery room personnel occupationally exposed to waste anaesthetic gases. Hum Exp Toxicol. 2018. https://doi.org/10.1177/096032 7118783532

2. Wiesner $G$, Schiewe-Langgartner F, Lindner R, Gruber M. Increased formation of sister chromatid exchanges, but not of micronuclei, in anaesthetists exposed to low levels of sevoflurane. Anaesthesia. 2008;63:861-4.

3. Herzog-Niescery J, Seipp HM, Weber TP, Bellgardt M. Inhaled anesthetic agent sedation in the ICU and trace gas concentrations: a review. J Clin Monit Comput. 2018;32:667-75.

4. Occupational Safety and Health Administration (OSHA). Anesthetic gases: guidelines for workplace exposures. 2000. http://www.osha.gov/dts/osta/ anestheticgases/index.html Accessed: 30 th November 2018.

5. Herzog-Niescery J, Botteck NM, Vogelsang H, Gude P, Bartz H, Weber TP, et al. Occupational chronic sevoflurane exposure in the everyday reality of the anesthesia workplace. Anesth Analg. 2015;121:1519-28.

6. Walder B, Lauber R, Zbinden AM. Accuracy and cross-sensitivity of 10 different anesthetic gas monitors. J Clin Monit. 1993;9:364-73.

7. Deutsches Institut für Normung, European Standard. International Organization for Standardization (DIN EN ISO): cleanrooms and associated controlled environments - part 3: test methods (ISO 14644). Berlin, Germany: Beuth Verlag $\mathrm{GmbH} ; 2017$.

8. Hoerauf K, Funk W, Harth M, Hobbhahn J. Occupational exposure to sevoflurane, halothane and nitrous oxide during paediatric anaesthesia.
Waste gas exposure during paediatric anaesthesia. Anaesthesia. 1997;52: 215-9.

9. Byhahn C, Heller K, Lischke V, Westphal K. Surgeon's occupational exposure to nitrous oxide and sevoflurane during pediatric surgery. World I Surg. 2001;25:1109-12.

10. Blokker-Veldhuis MJ, Rutten PM, De Hert SG. Occupational exposure to sevoflurane during cardiopulmonary bypass. Perfusion. 2011;26:383-9.

11. Schebesta K, Lorenz V, Schebesta EM, Hörauf K, Gruber M, Kimberger O, et al. Exposure to anaesthetic trace gases during general anaesthesia: CobraPLA vs. LMA classic. Acta Anaesthesiol Scand. 2010;54:848-54.

12. Luma Sense ${ }^{\oplus}$ Technologies. Innova $1412 \mathrm{i}$ multi-gas monitoring instruments. Manual. https://innova.lumasenseinc.com/manuals/1412i/. Accessed $30^{\text {th }}$ November 2018.

\section{Publisher's Note}

Springer Nature remains neutral with regard to jurisdictional claims in published maps and institutional affiliations.
Ready to submit your research? Choose BMC and benefit from:

- fast, convenient online submission

- thorough peer review by experienced researchers in your field

- rapid publication on acceptance

- support for research data, including large and complex data types

- gold Open Access which fosters wider collaboration and increased citations

- maximum visibility for your research: over $100 \mathrm{M}$ website views per year

At BMC, research is always in progress.

Learn more biomedcentral.com/submissions 